\section{Fast-track strategy for the prevention of Hb Bart's hydrops fetalis syndrome}

\author{
Narutchala Suwannakhon, ${ }^{1}$ \\ Khajohnsilp Pongsawatkul, ${ }^{2}$ \\ Teerapat Seeratanachot, ${ }^{3}$ \\ Wirawan Rasri, ${ }^{2}$ \\ Khwanruedee Mahingsa, ${ }^{4}$ \\ Arunee Pingyod, ${ }^{4}$ \\ Wanwipa Bumrungpakdee, ${ }^{4}$ \\ Torpong Sanguansermsri ${ }^{4}$
}

${ }^{1}$ Discipline of Biology, School of Science, University of Phayao, Phayao; ${ }^{2}$ Division of Obstetrics and Gynecology, Phayao

Hospital, Phayao; ${ }^{3}$ Discipline of

Biochemistry, School of Medical Science, University of Phayao, Phayao;

${ }^{4}$ Thalassemia Unit, University of

Phayao, Phayao, Thailand

\begin{abstract}
We propose a fast-track strategy [direct blood DNA analysis using a quantitative real-time polymerase chain reaction (PCR) technique] for the early risk detection and prenatal diagnosis of $\alpha(0)$-thalassemia (SEA and Thai deletion). Blood DNA samples were obtained from a volunteer group of 1235 ANC couples. They were assessed using quantitative real-time PCR to detect carriers of $\alpha(0)$-thalassemia (SEA and Thai deletion). At-risk couples were identified, and further prenatal diagnosis by amniocentesis was implemented. Fetal DNA was isolated from the amniotic cells and characterized by quantitative real-time PCR to detect the $\alpha(0)$-thalassemia mutation, which was reconfirmed using the droplet digital PCR method. Fifteen at-risk couples were identified. The timing of prenatal diagnosis was appropriate for all couples and four of the fetuses were diagnosed with Bart's hydrops fetalis. The results were compatible with those calculated using the Hardy-Weinberg equation for a recessively inherited single gene disorder. The conclusion was that the fast-track strategy could shorten screening policy timelines, promoting early risk detection for couples and early prenatal diagnosis. The fast-track strategy might be beneficial for the prevention of hemoglobin Bart's hydrops fetalis syndrome.
\end{abstract}

\section{Introduction}

Hemoglobin Bart's hydrops fetalis syn- drome is the most severe form of $\alpha$-thalassemia and is almost always lethal. This syndrome is primarily associated with homozygous $\alpha(0)$-thalassemia ( $\alpha^{0}$-thalassemia). It is sporadically reported in all Southeast Asian countries with a prevalence of 1-3 cases per thousand pregnancies. An affected fetus succumbs within the uterus 6 to 8 month gestation, and the mother may develop fatal postpartum complications. To avoid serious and unpredicted maternal risk, early prenatal diagnosis (PND) and pregnancy interruption is often necessary. ${ }^{1-3}$

In northern Thailand, the SEA type of $\alpha^{0}$-thalassemia deletion carrier can be detected in as much as $15 \%$ of the population, whereas the Thai type of $\alpha^{0}$-thalassemia deletion carrier was detected in less than $0.1 \%$. Unfortunately, the reported success rate of the major thalassemia disease prevention strategy was less than $50 \%$, despite the full support of the program. The clinical histories of mothers with affected fetuses with hemoglobin Bart's hydrops fetalis syndrome indicated that a major area of failure in the prevention of this disorder is due to unsatisfactory local policies..$^{4,5}$

To enhance and improve the process of at-risk couple identification, a quantitative real-time PCR technique (fast-track strategy) for the detection of $\alpha^{0}$-thalassemia (SEA and Thai deletion) carrier was applied to all pregnant women and their spouses. The modified strategy might improve the early risk detection and early PND.

\section{Materials and Methods}

After approval was received from the institutional Research Ethics Committee, blood samples were collected from the volunteer pregnant women and their spouses from the antenatal care clinic at the Phayao Provincial Hospital in Thailand. Recruitment was carried out from January 2015 to August 2016, and included 1235 pregnancies. The average fetal age at the time of registration was $10 \pm 3$ weeks.

\section{Workflow}

Three $\mathrm{ml}$ of blood was collected from each volunteer and transferred to the Thalassemia Unit, University of Phayao to detect carriers of $\alpha^{0}$-thalassemia (SEA and Thai deletion). Blood DNA isolation was carried out following the Chelex method with some minor modifications. ${ }^{6}$ Each DNA sample was tested for $\alpha^{0}$-thalassemia (SEA and Thai deletion) by multiplex realtime PCR. Couples at risk of having a fetus with hemoglobin Bart's hydrops fetalis syndrome were counseled and subject to prena-
Correspondence: Narutchala Suwannakhon, Discipline of Biology, School of Science, University of Phayao, Phayao, Thailand. Tel.: +66.0.810296551 - Fax: +66.0.54466724.

E-mail: Narutchala@gmail.com

Key words: Fast-track diagnosis; $\alpha(0)$-thalassemia (SEA and Thai deletion) carriers; prevention of $\mathrm{Hb}$ Bart's hydrops fetalis syndrome.

Acknowledgments: this work was supported in part by the University of Phayao endowment fund.

Contributions: NS, TS 1, TS 2, conception and design; NS, KP, WR, acquisition of data; NS, $\mathrm{KM}$, AP, WB, development of methodology and sample tests; NS, TS 1,KP, analysis and interpretation of data; NS, TS 1, TS 2, writing, review and/or revision of the manuscript; NS, study supervision; TS 2 , research consultants.

Conflict of Interest: the authors declare no potential conflict of interest.

Received for publication: 7 February 2017.

Revision received: 21 August 2017.

Accepted for publication: 24 August 2017.

This work is licensed under a Creative Commons Attribution 4.0 License (by-nc 4.0).

(C) Copyright N. Suwannakhon et al., 2017

Licensee PAGEPress, Italy

Thalassemia Reports 2017; 7:6620

doi:10.4081/thal.2017.6620

tal diagnosis by amniocentesis. ${ }^{7}$ The fetal DNA was isolated from amniotic cells. The fetal $\alpha^{0}$-thalassemia mutation was identified by multiplex real-time PCR and was confirmed by the droplet digital PCR (ddPCR) technique. $^{8}$

\section{Blood DNA extraction (Chelex method)}

Blood $(50 \mu \mathrm{L})$ was mixed with $1 \mathrm{ml}$ of $0.5 \%$ Triton $\mathrm{X}-100$ in a $1.5 \mathrm{ml}$ tube, vortexed and then and centrifuged at 14,000 RPM for $1 \mathrm{~min}$. The supernatant was removed, and a volume of approximately 20 $\mu 1$ was recovered. Water $(1 \mathrm{ml})$ was added, and the sample was vortexed and centrifuged, and approximately $20 \mu \mathrm{l}$ supernatant was recovered. Subsequently, $300 \mu 1$ $10 \%$ Chelex suspended in water (Bio-Rad Laboratories, Hercules, CA, USA) and 110 $\mu 1$ of water were added to the sample. The mixture was incubated at $56^{\circ} \mathrm{C}$ for $1 \mathrm{~h}$ or overnight. After boiling for $5 \mathrm{~min}$, the supernatant that contained the extracted DNA was collected and stored at $-20^{\circ} \mathrm{C}$ until analysis. 


\section{Quantitative real-time PCR}

For the diagnosis of the SEA and Thai deletions, multiplex quantitative real-time PCR primers and condition were performed in according to the previous protocol. ${ }^{7,9}$ In brief, the PCR mixtures $(25 \mu \mathrm{L})$ included 5 $\mu 1$ of DNA, 1X PCR buffer, $1.5 \mu \mathrm{M} \mathrm{MgCl}_{2}$, $200 \mu \mathrm{M}$ of each dNTP, $2 \mu \mathrm{M}$ of SYTO9, 1 unit of Platinum ${ }^{\circledR}$ Taq DNA polymerase, and $0.2 \mu \mathrm{M}$ of each primer of P1, P2, P3, $\mathrm{TF}$, and TR. Thermal cycling was performed on the platform of a Bio-Rad CFX96 real-time system (Bio-Rad Laboratories, California, USA) beginning at $94^{\circ} \mathrm{C}$ for two minutes to activate the Taq DNA polymerase, followed by 40 cycles of denaturing at $94^{\circ} \mathrm{C}$ for $15 \mathrm{~s}$, annealing at $64^{\circ} \mathrm{C}$ for $15 \mathrm{~s}$, and extension at $72^{\circ} \mathrm{C}$ for 20 s. Fluorescence was measured on the SYBR channel $(533 \mathrm{~nm})$ at the end of each cycle.

\section{Droplet digital PCR}

The method was applied to diagnose fetuses at risk for hemoglobin Bart's hydrops fetalis syndrome. Genomic DNA was isolated from the amniotic cells according to the manufacturer's protocol using the QIA-amp DNA Mini Kit (QIAGEN, Hilden, Germany). The isolated DNA was diluted with $1 \times$ PCR buffer to $5 \mathrm{ng} / \mu \mathrm{l}$ and stored at $-20^{\circ} \mathrm{C}$ until analysis. The gene quantification of the wild-type and SEA genes were analyzed according to the manufacturer's protocol using the Bio-Rad QX100 Droplet Digital PCR system. The workflow included preparation of the PCR reaction mixture $(20 \mu \mathrm{l})$ by combining ddPCR 2X PCR Master Mix, 20X Primers (P1, P2 and P3), Taqman Probe Mix (P1P2 probe and $\mathrm{P} 1 \mathrm{P} 3$ probe, Applied Biosystems, USA) (Table 1) and $5 \mu 1$ of the DNA sample. The combination of the PCR reaction mixture and oil were generated in a droplet generator. The ddPCR droplet samples were transferred to a PCR plate and were amplified in a Bio-Rad CFX96 real-time system (Bio-Rad Laboratories, California, USA). After PCR amplification, the PCR plate was placed in a QX100 droplet reader. The droplet reader and QuantaSoft software enumerate the PCR-positive and PCR-negative droplets to provide absolute quantification of target DNA.

\section{Results}

There were 1,235 couples enrolled in the fast-track strategy to prevent $\alpha^{0}$-thalassemia-thalassemia. Three patterns were detected in the $\alpha^{0}$-thalassemia (SEA and Thai deletion) carriers by real-time PCR. The control wild-type DNA revealed a single peak with a melting point of $92.4^{\circ} \mathrm{C}$,
A

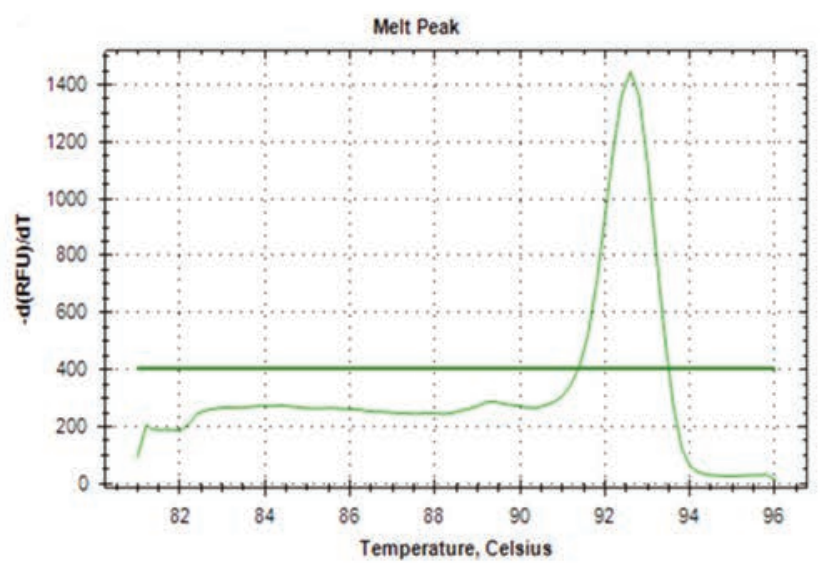

B

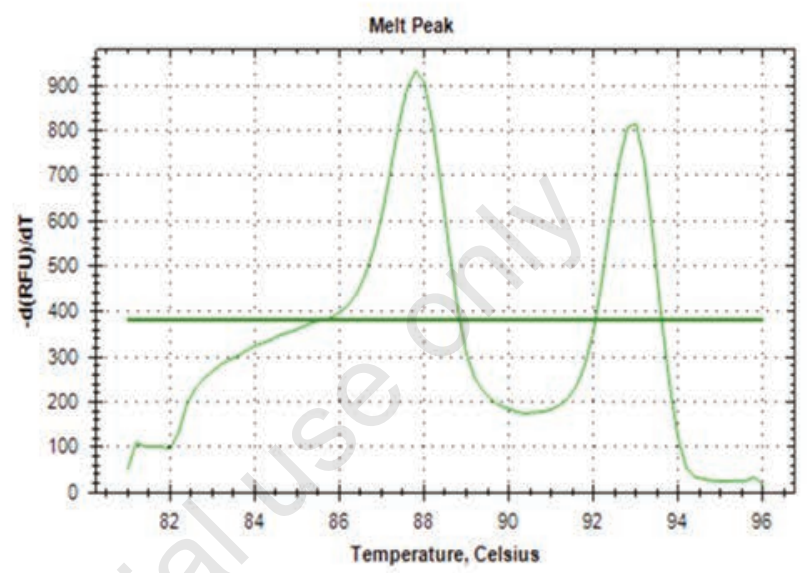

C

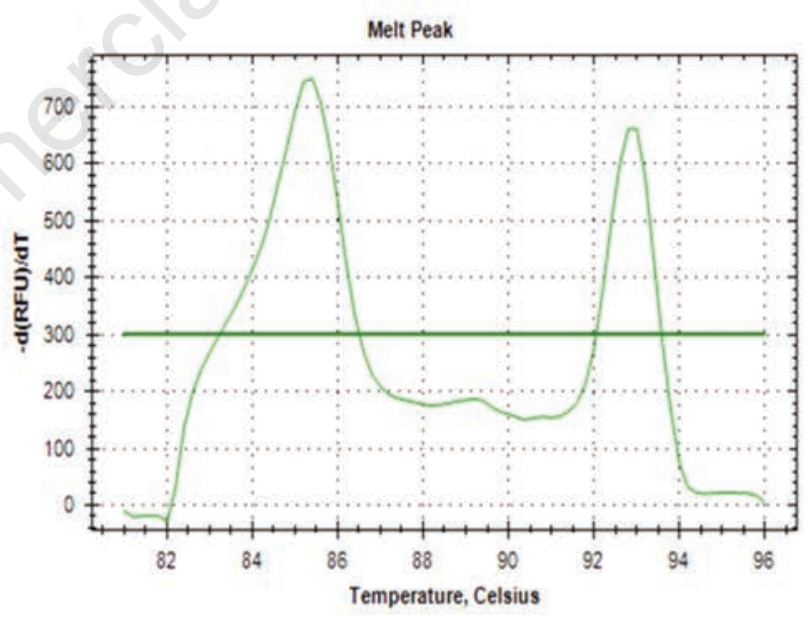

Figure 1. Here shows chromatograms using the quantitative real-time PCR. The control wild type DNA show only an image of single melt peak with a melting point of $92.4{ }^{\circ} \mathrm{C}$ (A) while SEA and Thai trait demonstrated the double melt peaks with melting points of $87.4^{\circ} \mathrm{C}$ with $92.4^{\circ} \mathrm{C}(\mathrm{B})$ and $85.4^{\circ} \mathrm{C}$ with $92.4^{\circ} \mathrm{C}(\mathrm{C})$, respectively.

Table 1 Sequence and location of the ddPCR primers and Taqman probes.

\begin{tabular}{lll} 
Name & Nucleotides $(5->3)$ & NCBI ref. Number \\
Primer (P1) & GTCGTCCCCACTGTCGTC & Z84721, 26202-19 \\
Primer (P2) & ACGCCGTCCGACTCAAGGA & Z84721, 26334-53 \\
\hline Primer (P3) & GGCTTACTGCAGCCTTGAAC & Z69706, 2647-67 \\
P1P2 probe & FAM-TCT AGC CCC TGA GCA CCG- MGBNFQ & - \\
\hline P1P3 probe & VIC-CTC CAA GTG AAC CTC C-MGBNFQ & - \\
\hline
\end{tabular}


while the SEA and Thai traits demonstrated double peaks with melting points of $87.4^{\circ} \mathrm{C}$ and $92.4^{\circ} \mathrm{C}$, or $85.4^{\circ} \mathrm{C}$ and $92.4^{\circ} \mathrm{C}$, respectively (Figure 1). The melt peaks images and melting temperatures (Tm) were specifically for carriers of the $\alpha^{0}$-thalassemia SEA and Thai deletion. The application of the droplet digital PCR technique for the PND of $\alpha^{0}$-thalassemia show three types of droplets detected, namely droplets with FAM- fluorescence, droplets with VIC- fluorescence and droplets with both FAM and VIC fluorescence. The average amount of FAM (indicative of the wild-type gene) detected in a normal subject was 209 copies $/ \mu \mathrm{L}$, while the amount of VIC (indicative of $\mathrm{Hb}$ Bart's hydrops fetalis fetus) detected was $226 \mathrm{copy} / \mu \mathrm{L}$, and the count for the SEA trait (FAM and VIC) was 237:255. The image of the two-dimension chromatogram, generated using the QuantaSoft program, revealed specific patterns for a normal fetus, $\alpha^{0}$-thalassemia (SEA deletion) carrier and $\mathrm{Hb}$ Bart's hydrops fetalis fetus (Figure 2).

Of the 1235 couples, 15 couples were at risk of having a fetus homozygous for $\alpha^{0}-t$ halassemia (SEA deletion). All couples underwent PND by amniocentesis. The PND was assessed by the droplet digital PCR technique and revealed 4 cases that were homozygous for $\alpha^{0}$-thalassemia (SEA deletion). Of the other cases, 3 were normal and 8 were SEA deletion carriers. The PND diagnosed by quantitative real-time PCR of all 15 cases were concordant with droplet digital PCR analysis. The prevalence of the $\alpha^{0}$-thalassemia SEA deletion carrier calculated using the Hardy-Weinberg equation for a recessively inherited single gene disorder was $11 \%$.

\section{Discussion}

The prevalence of $\alpha^{0}$-thalassemia deletion carriers (involving a deletion of the duplicated $\alpha$-globin genes) is in the average of $5 \%$ ( 3 to $12 \%$ ) but may be as high as $15 \%$ in some ethnic of northern Thailand. This indicates that the 8-16 of every 1000 pregnant women are at risk of having a fetus with $\mathrm{Hb}$ Bart's hydrops fetalis. ${ }^{2,10-12}$ In this study, the prevalence of the $\alpha^{0}$-thalassemia SEA deletion carrier was $11 \%$. Homozygous $\alpha^{0}$-thalassemia is often fatal in utero due to severe hydrops fetalis. Although in utero transfusions are increasingly used to allow fetal survival in $\mathrm{Hb}$ Barts hydrops fetalis syndrome, however the management of pre- and postnatal outcomes are not well established. ${ }^{13,14}$ To avoid the severe toxemia complications associated with hydropic fetuses, early prenatal diagnosis is necessary. Since 2005 , the con- ventional thalassemia prevention program has been fully established and supported. However, the surveillance reported after 5 years of the prevention program revealed the success rate was $50 \%$ lower than expected. Meanwhile, sporadic cases of the full-blown $\mathrm{Hb}$ Bart's hydrops fetalis syndrome have been reported every year. Furthermore, evidence the controlled tha- lassemia prevention program study of the conventional thalassemia prevention program within the past year revealed the success rate was approximately $30 \%$ (one affected in 1127 expectants). There are many factors contributing to the ineffectiveness. The major factor might be related to the complexity of the program activity, which requires various groups of special-

A

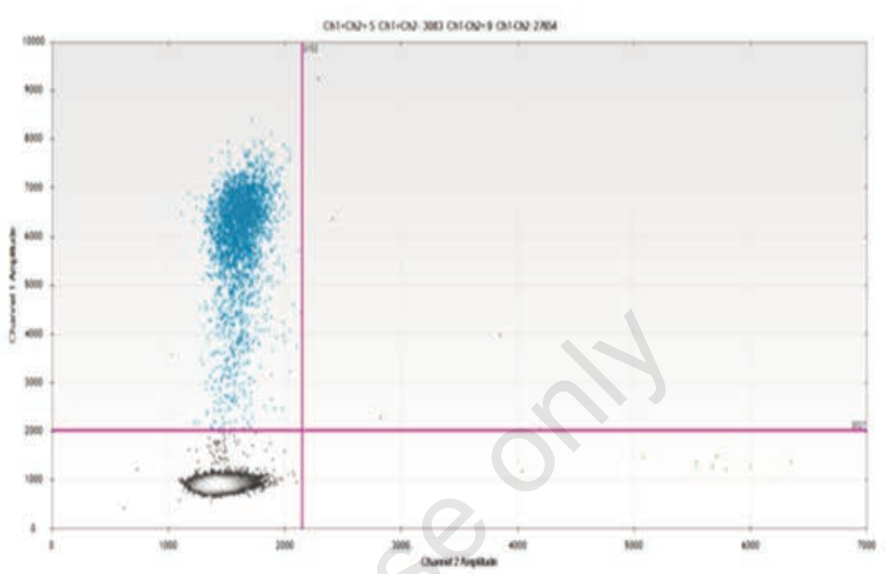

B

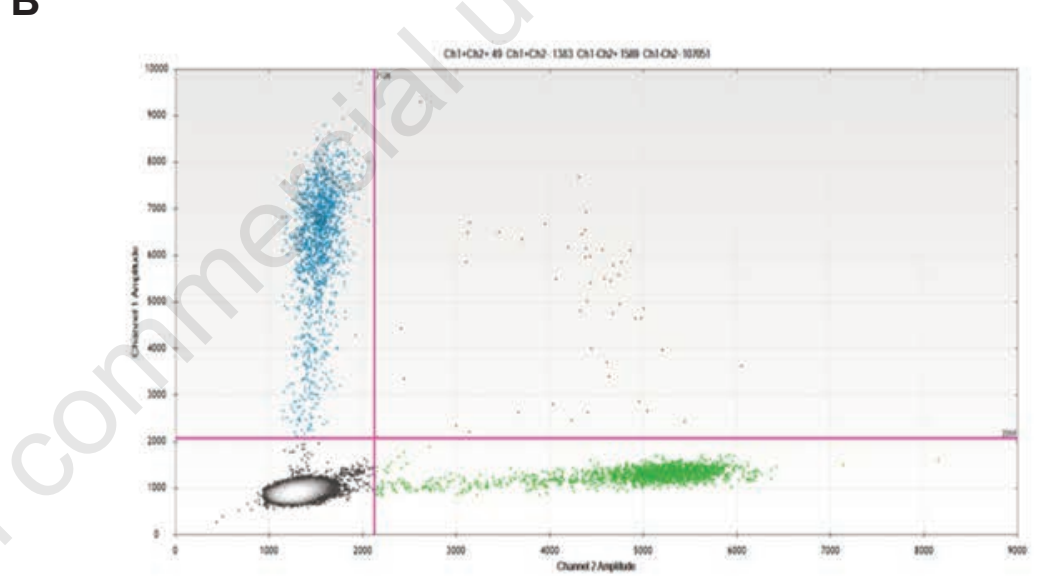

C

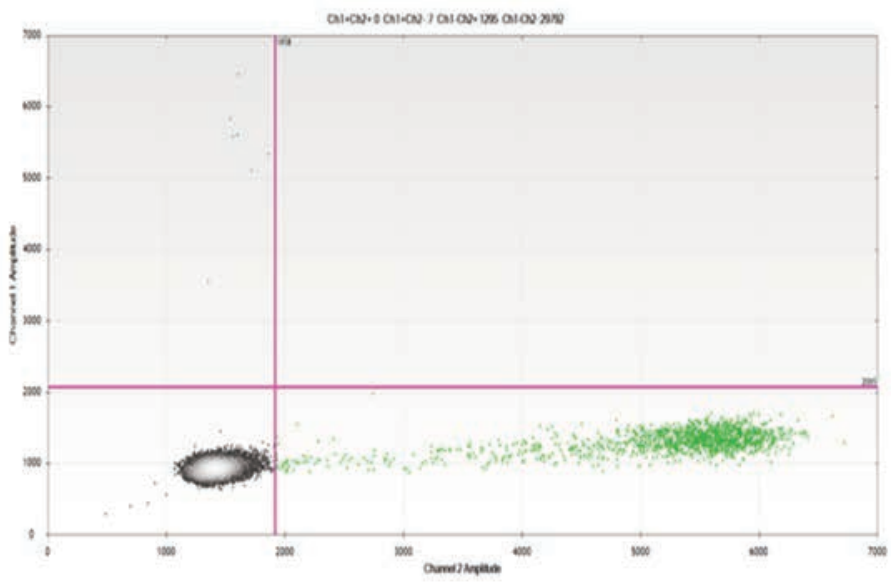

Figure 2. Here shows the image of the two-dimension chromatograms, generated using the QuantaSoft program, revealed specific patterns for a normal fetus (A), $\alpha 0$-thalassemia (SEA deletion) carrier (B) and Hb Bart's hydrops fetalis fetus (C). 
ists, including a thalassemia counselor, CBC-lab technologist, molecular technologist, a hematologist and an obstetrics/gynecology. An abnormal sample will be examined by all these specialists. The turnaround time for recruiting an at-risk couple might be prolonged by $8-10$ weeks, which could affect PND by CVS or amniocentesis. Moreover, co-inheritance of $\beta$-thalassemia trait with the $\alpha^{0}$-thalassemia trait has a significant effect on the red cell indices, particularly the MCV and $\mathrm{MCH}$, which may be normalized. In such a case, the $\alpha^{0}$-thalassemia trait might scape further evaluation. ${ }^{15}$

On the other hand, the fast-track strategy uses real-time PCR technology to assess $\alpha^{0}$-thalassemia (SEA and Thai deletion) carrier directly from the blood DNA of pregnant couples. The quantitative real-time PCR technique used for the identification of $\alpha^{0}$-thalassemia (SEA and Thai deletion) carriers is a simple molecular technology. The method is highly accurate and allows for the rapid detection of at-risk couples; 96 to 384 samples could be assessed within one day. Therefore, an early at-risk detection and prenatal diagnosis are possible. In this study, the fast-track strategy was applied to 1235 volunteer expectant couples. Fifteen at-risk couples were identified and were informed within one week. The strategy developed was applicable for the thalassemia counselors. All at-risk women were satisfied with the service and requested more PND.

\section{Conclusions}

The fast-track strategy could shorten screening policy timelines, promoting early at-risk detection and prenatal diagnosis. The fast-track strategy might increase the feasi- bility of $\alpha^{0}$-thalassemia carrier screening, which might be beneficial in the prevention of hemoglobin Bart's hydrops fetalis syndrome.

\section{References}

1. Tongsong T, Wanapirak C, Sirivatanapa $\mathrm{P}$, et al. Prenatal eradication of $\mathrm{Hb}$ Bart's hydrops fetalis. Reprod Med J 2001;46:18-22.

2. Ratanasiri T, Komwilaisak R, Sittivech $\mathrm{A}$, et al. Incidence, causes and pregnancy outcomes of hydrops fetalis at Srinagarind Hospital, 1996-2005: a 10year review. J Med Assoc Thai 2009;92:594-9.

3. Takci S, Gharibzadeh M, Yurdakok M, et al. Etiology and outcome of hydrops fetalis: report of 62 cases. Pediatr Neonatol 2014;55:108-13.

4. Nipaporn S, Sirasoonthornm P, Pannarunothai S. Experiences of pregnant women at risk of having babies with severe thalassemia in Phitsanulok Province, Thailand. J Pub Health Dev 2011;9:18-28.

5. Chaibunruang A, Prommetta S, Yamsri $\mathrm{S}$, et al. Molecular and hematological studies in a large cohort of $\alpha(0)$-thalassemia in northeast Thailand: data from a single referral center. Blood Cells Mol Dis 2013;51:89-93.

6. Walsh PS, Metzger DA, Higuchi R. Chelex 100 as a medium for simple extraction of DNA for PCR-based typing from forensic material. BioTechniques 1991;10:506-13.

7. Seeratanachot T, Sanguansermsri T, Shimbhu D. Detection of $\mathrm{Hb} \mathrm{H}$ disease, genotypes common in northern Thailand by quantitative real-time polymerase chain reaction and high resolu- tion melting analyses. Hemoglobin 2013;37:574-83.

8. Pornprasert S, Prasing W. Detection of alpha (0)-thalassemia South-East Asian-type deletion by droplet digital PCR. Eur J Haematol 2014;92:244-8.

9. Suwannakhon N, Seeratanachot T, Mahingsa K, Sanguansermsri T. Molecular diagnosis of $\alpha 0$-thalassemia through urine DNA: A novel DNA source to facilitate prevention programs in remote geographical areas. Hemoglobin 2015;39:270-3.

10. Lemmens-Zygulska M, Eigel A, Helbig $\mathrm{B}$, et al. Prevalence of alpha-thalassemias in northern Thailand. Hum Genet 1996;98:345-7.

11. Pharephan S, Sirivatanapa P, Makonkawkeyoon S, et al. Prevalence of $\alpha$-thalassaemia genotypes in pregnant women in northern Thailand. Indian J Med Res 2016;143:315-22.

12. Kulaphisit M, Kampuansai J, Leecharoenkiat K, et al. A comprehensive ethnic-based analysis of alpha thalassaemia allelle frequency in northern Thailand. Sci Rep 2017;5:4690.

13. Derderian SC, Jeanty C, Walters MC, et al. In utero hematopoietic cell transplantation for hemoglobinopathies. Front Pharmacol 2015;5:278.

14. Kreger EM, Singer ST, Witt RG, et al. Favorable outcomes after in utero transfusion in fetuseswith alpha thalassemia major: a case series and review of the literature. Prenat Diagn 2016;36:12429.

15. Viprakasit V, Limwongse C, Sukpanichnant $\mathrm{S}$, et al. Problems in determining thalassemia carrier status in a program for prevention and control of severe thalassemia syndromes: a lesson from Thailand. Clin Chem Lab Med 2013;51:1605-14. 